\title{
SEBARAN DAN HABITAT JUVENIL UDANG PENAEID DI PERAIRAN KUBU RAYA, KALIMANTAN BARAT
}

\section{DISTRIBUTION AND HABITAT PREFERENCE OF JUVENILE PENAEID SHRIMPS IN KUBU RAYA WATERS, WEST KALIMANTAN}

\author{
Dimas Angga Hedianto, Sri Endah Purnamaningtyas dan Riswanto \\ Peneliti pada Balai Penelitian Pemulihan dan Konservasi Sumber Daya Ikan, Jatiluhur \\ Teregistrasi I tanggal: 27 Januari 2014; Diterima setelah perbaikan tanggal: 06 Agustus 2014; \\ Disetujui terbit tanggal: 08 Agustus 2014 \\ e-mail: dimas_brpsi@yahoo.com
}

\begin{abstract}
ABSTRAK
Tingkat keterkaitan juvenil udang terhadap habitat dapat dijadikan salah satu dasar untuk penentuan kawasan daerah asuhan. Penelitian tentang sebaran dan keterkaitan antara juvenil udang penaeid dengan habitatnya dilakukan di perairan Kubu Raya, Kalimantan Barat pada bulan Juni, September, November (tahun 2012) dan bulan April, Juli, Oktober (tahun 2013). Pengambilan sampel dilakukan dengan metode sapuan (swept area method) menggunakan mini beam trawl. Indeks constancy dan fidelity digunakan untuk mengetahui pola sebaran dan derajat keterkaitan udang penaeid dengan habitatnya sebagai dasar penentuan daerah asuhan juvenil udang. Identifikasi juvenil udang diperoleh 3 genera dan 12 spesies. Kelimpahan total tertinggi berasal dari genus Metapenaeus (70,5\%), diikuti genus Parapenaeopsis (29,3\%) dan Fenneropenaeus (0,2\%). Juvenil udang dari genera tersebut memiliki pola sebaran dan preferensi habitat yang berbeda karena memiliki perbedaan pola daur hidup. Juvenil udang wangkang ( $F$. indicus) memiliki derajat keterkaitan dengan kategori sangat tinggi di perairan Tanjung Bunga Dalam, sedangkan derajat keterkaitan dengan kategori medium terdapat di perairan Tanjung Intan dan Pulau Dabung. Habitat daerah asuhan udang wangkang terutama terdapat di daerah estuari dengan kerapatan mangrove cukup tinggi, mendapat massa air tawar secara langsung dengan tipe substrat pasir bercampur lumpur dan serasah. Udang dogol putih (M. elegans) dan udang rotan (P. gracillima) memiliki derajat keterkaitan dengan kategori medium di perairan Tanjung Tempurung. Habitat daerah asuhan yang disenangi adalah daerah estuaria yang memiliki banyak masukan massa air tawar dan air laut atau sangat dipengaruhi oleh proses pasang-surut dengan tipe substrat terdiri dari lumpur dan pasir serta banyak serasah.
\end{abstract}

Kata Kunci: Juvenil, udang penaeid, Kubu Raya

\section{ABSTRACT}

Habitat preference of juvenile shrimps as an indicator to determine of main shrimp nursery ground. Study on distribution and habitat preference of juvenile penaeid shrimps in Kubu Raya waters, West Kalimantan were carried out on June, September, November (2012) and April, July, October (2013). Sampling was conducted with a sweep area method using a mini beam trawl. Distribution pattern and habitat preference of juvenile shrimps were analyzed by constancy and fidelity index. Identification of juvenile penaeid shrimp consisted of 3 genera and 12 species with the highest of total abundance from genus of Metapenaeus (70.5\%), followed by Parapenaeopsis (29.3\%) and Fenneropenaeus (0.2\%). Juvenile shrimp for those genera have different distribution patterns in certain habitats because of different life cycle pattern. The habitat preference of indian white shrimp juvenile ( $F$. indicus) in the waters of Tanjung Bunga Dalam have very high category. Meanwhile, in the waters of Tanjung Intan and Pulau Dabung has medium category. The main nursery ground of F. indicus were estuaries with high enough of mangrove density and most affected by freshwater discharge with the dominant substrate type is sand as sandly mud and mix with litters. The habitat preference of Juvenile of fine shrimp (M. elegans) and thin shrimp (P. gracillima) have medium category in the waters of Tanjung Tempurung. The main nursery ground character needs estuaries that have a lot of freshwater and saltwater mass input depending on the tides with substrate type are mud, sand and mix with litters.

Keywords: Juvenile, penaeid shrimp, Kubu Raya

\section{PENDAHULUAN}

Sektor perikanan merupakan salah satu program unggulan dari Kabupaten Kubu Raya, Kalimantan Barat. Hal ini ditunjang oleh tingginya potensi sumberdaya pesisir, banyaknya muara sungai, kekhasan biodiversitas estuaria dan luasnya hutan mangrove yang terdapat di wilayah tersebut (Dinas Perikanan \& Kelautan Kabupaten Kubu Raya, 2011). Udang penaeid merupakan salah satu komoditas perikanan yang bernilai ekonomis dan menjadi target nelayan di sekitar Sungai Kakap, Pontianak (Saptoyo, 2006). Penelitian yang telah dilakukan di 
perairan Pemangkat, Kalimantan Barat diketahui hasil tangkapan udang didominasi oleh famili Penaeidae (Wedjatmiko et al., 2011). Jenis udang penaeid yang penting di perairan tersebut meliputi Metapenaeus sp., Metapenaeopsis sp., Parapenaeopsis sp. dan Fenneropenaeus sp. (Kembaren, 2012). Lebih lanjut, jenis udang ekonomis lainnya di perairan Kubu Raya adalah udang putih/ambai (Metapenaeus lysianassa) (Saptoyo, 2006).

Peningkatan permintaan pasar dan ketergantungan masyarakat pesisir untuk memenuhi kebutuhan hidup dari sektor perikanan menyebabkan terjadinya penangkapan sumberdaya ikan yang intensif, khususnya komoditas udang. Hal ini terjadi pula di sekitar perairan Kubu Raya, dimana usaha penangkapan udang banyak menggunakan alat tangkap pasif (seperti jermal, ambai, tuguk) maupun aktif (seperti lampara dasar yang ditarik menggunakan kapal berukuran <10 GT). Berdasarkan data statistik perikanan Kabupaten Kubu Raya tahun 2010-2012, produksi udang cenderung dari 5.170 ton (tahun 2010) menjadi 13.186 ton (tahun 2012). Kondisi tersebut menunjukkan tingkat eksploitasi yang tinggi. Apabila tidak dilakukan pengelolaan dan pengawasan terhadap pemanfaatan sumberdaya udang dengan baik, maka dapat menyebabkan tangkap lebih (over exploitation). Oleh karena itu, perlu dilakukan pengelolaan yang rasional berdasarkan kajian ilmiah agar sumber daya udang tetap lestari dan berkelanjutan.

Salah satu upaya pengelolaan sumber daya udang adalah melalui fisheries refugia ditujukan untuk melindungi proses daur hidup udang pada habitat yang kritis, terutama di daerah asuhan (nursery ground) (UNEP, 2007). Konsep fisheries refugia telah dikembangkan di perairan Laut China Selatan dan Teluk Thailand, sebagai upaya konservasi stok ikan dan udang (UNEP, 2009). Penelitian ini bertujuan untuk menganalisis sebaran dan keterkaitan juvenil udang penaeid dengan habitatnya di perairan Kabupaten Kubu Raya, Kalimantan Barat. Hasil dari penelitian ini diharapkan dapat menjadi informasi dasar untuk penetapan fisheries refugia di daerah asuhan udang.

\section{METODEPENELITIAN}

Penelitian dilaksanakan pada bulan Juni, September dan November (tahun 2012) dan bulan April, Juli dan Oktober (tahun 2013) di perairan Kabupaten Kubu Raya, Kalimantan Barat. Pengumpulan data dilakukan di delapan lokasi sampling yang ditentukan secara acak berlapis (stratified random sampling) (Nielsen \& Johnson, 1985) (Gambar 1).

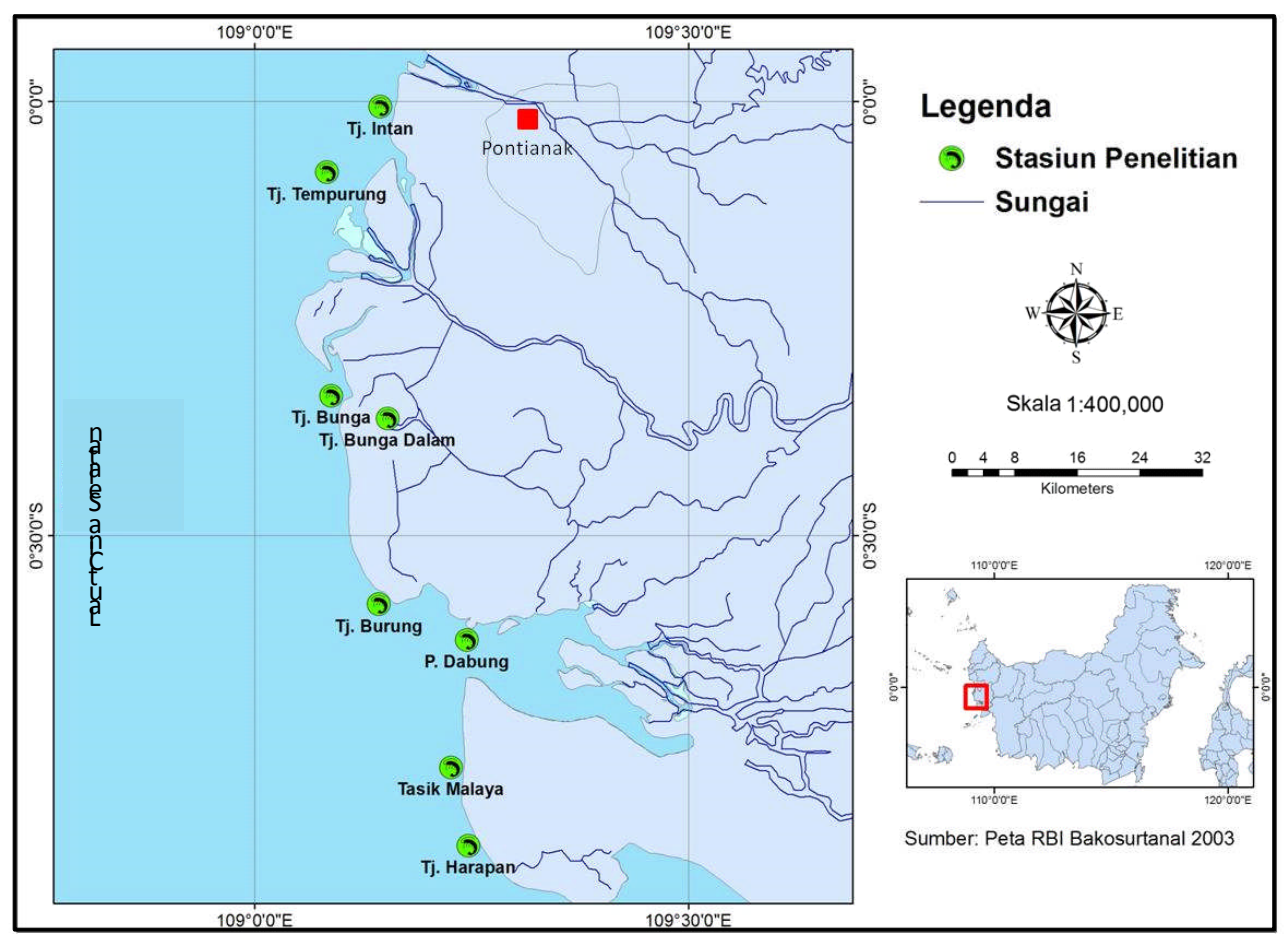

Gambar 1. Peta lokasi stasiun penelitian di perairan Kubu Raya.

Figure 1. Map showing research station in Kubu Raya waters. 
Pengambilan sampel juvenil udang dilakukan pada siang hari menggunakan mini beam trawl berukuran mata jaring bagian kantong 0,75 inci yang ditarik selama 10 menit dengan kecepatan kapal rata-rata 2 knot/jam. Juvenil diawetkan menggunakan larutan formalin $10 \%$. Identifikasi jenis udang penaeid mengacu pada FAO (Holthuis, 1980; Fischer \& Bianchi, 1984; Chan, 1998) dan situs Sealifebase (Palomares \& Pauly, 2012).

Kelimpahan juvenil udang diperoleh menggunakan metode sapuan (swept area method) sesuai dengan Spare \& Venema (1992), yaitu:

$$
\begin{aligned}
& \mathbf{a}=\text { V.t.hr. } X_{2} \\
& \mathbf{D}=\mathbf{n} / \mathbf{a} \ldots \ldots \ldots
\end{aligned}
$$

Keterangan:

$$
\begin{aligned}
\mathrm{D}= & \text { kelimpahan udang }\left(\mathrm{ind} / \mathrm{km}^{2}\right) \\
\mathrm{n}= & \text { jumlah udang yang tercacah (ind) } \\
\mathrm{a}= & \text { luas sapuan }\left(\mathrm{km}^{2}\right) \\
\mathrm{V}= & \text { rata-rata kecepatan kapal saat menarik jaring } \\
& (\text { knot/jam) } \\
\mathrm{t}= & \text { lama penarikan jaring (jam) } \\
\mathrm{hr}= & \text { panjang tali ris atas }(\mathrm{m}) \\
\mathrm{X}_{2}= & \text { fraksi panjang tali ris atas }
\end{aligned}
$$

Beberapa parameter kualitas air diukur untuk analisis pengelompokkan habitat. Parameter kualitas air yang diukur tersaji pada Tabel 1.

Analisis pengelompokkan (dendrogram) habitat dan kelompok juvenil udang berdasarkan pada jarak euclidean pautan lengkap (complete linkage) (Krebs, 1989) menggunakan program Statistica 8.0. Pengkajian pola keberadaan dan keterkaitan juvenil udang dengan habitatnya menggunakan analisis nodul yang menghubungkan antara kelompok udang dengan kelompok habitatnya. Analisis nodul yang digunakan adalah indeks constancy dan fidelity (Boesch, 1977). Indeks constancy adalah kecenderungan keberadaan kelompok spesies tertentu di suatu habitat pada setiap kemungkinan kejadian, sedangkan indeks fidelity adalah suatu ukuran yang menunjukkan tingkat keterkaitan dan pemilihan dari spesies tertentu terhadap habitat tertentu. Indeks constancy dan fidelity dihitung menggunakan persamaan:

$$
\begin{gathered}
C i j=\frac{a_{i j}}{\left(n_{i} \cdot n_{j}\right)} \cdots \cdots \\
F i j=\frac{\left(a_{i j} \cdot \sum{ }_{j} n_{j}\right)}{\left(n_{j} \cdot \sum a_{i j}\right)}
\end{gathered}
$$

Keterangan:

$\mathrm{C}_{\mathrm{ij}}=$ indeks constancy kelompok jenis-i pada kelompok habitat-j

$\mathrm{F}_{\mathrm{ij}}=$ indeks fidelity kelompok jenis-i pada kelompok habitat-j

$\mathrm{a}_{\mathrm{ij}}=$ jumlah anggota kelompok jenis-i pada kelompok habitat-j

$\mathrm{n}_{\mathrm{i},} \mathrm{n}_{\mathrm{j}}=$ jumlah seluruh kelompok jenis dan atau kelompok habitat

\section{HASIL DAN BAHASAN \\ HASIL}

\section{Sebaran, Kelimpahan dan Pengelompokkan Juvenil Udang Penaeid}

Secara umum, kelimpahan rata-rata juvenil udang yang diperoleh selama penelitian berkisar antara 41.548-145.076 ind $/ \mathrm{km}^{2}$ (Lampiran 1). Kelimpahan tertinggi (>100.000 ind/ $\mathrm{km}^{2}$ ) terdapat di stasiun penelitian Tanjung Bunga, Pulau Dabung dan Tanjung Harapan (Gambar 2).

Juvenil udang penaeid yang diidentifikasi terdiri dari 3 genera (Fenneropenaeus, Metapenaeus dan Parapenaeopsis) dan 12 spesies. Udang Metapenaeus memiliki kelimpahan yang tinggi dibandingkan dengan genus lainnya di setiap stasiun, kecuali di stasiun Tanjung Tempurung. Kelimpahan genus Parapenaeopsis tertinggi terdapat di daerah Tanjung Tempurung. Genus Metapenaeus dan Parapenaeopsis menyebar pada seluruh stasiun penelitian. Genus Fenneropenaeus hanya ditemukan di daerah stasiun Tanjung Intan dan Tanjung Bunga Dalam dengan rata-rata kelimpahan relatif rendah (Gambar 3).

Secara umum, udang ambai (Metapenaeus lysianassa) dan udang dogol (Metapenaeus affinis) tersebar di seluruh stasiun. Udang ambai memiliki kelimpahan tertinggi dengan rata-rata persentase keberadaan $\pm 56,9 \%$ di seluruh stasiun pengamatan. Jenis udang ini terutama melimpah di daerah Pulau Dabung. Udang merah (Parapenaeopsis hungerfordi) dan udang burik (Parapenaeopsis sculptilis) tersebar di seluruh lokasi penelitian dengan rata-rata kelimpahan rendah hingga medium. Udang wangkang (Fenneropenaeus indicus) hanya ditemukan di daerah Tanjung Intan dan Tanjung Bunga Dalam (Lampiran 1). Pengelompokkan (dendrogram) juvenil udang penaeid yang didasarkan pada sebaran dan kelimpahannya menurut stasiun pengamatan didapatkan sebanyak 7 (tujuh) kelompok (Gambar 4).

\section{Pola Keberadaan dan Keterkaitan Udang Penaeid terhadap Habitat}

Pengelompokkan (dendrogram) stasiun pengamatan berdasarkan kualitas dasar perairan (Lampiran 2) 
Tabel 1. Parameter yang diukur, alat dan metode pengumpulan data

Table 1. The parameters measured, tools and methods of data collection

\begin{tabular}{clcl}
\hline $\begin{array}{c}\text { No/ } \\
\text { No }\end{array}$ & \multicolumn{1}{c}{$\begin{array}{c}\text { Parameter/ } \\
\text { Parameter }\end{array}$} & $\begin{array}{c}\text { Satuan/ } \\
\text { Unit }\end{array}$ & \multicolumn{1}{c}{$\begin{array}{c}\text { Alat dan Metode/ } \\
\text { Tools and Methods }\end{array}$} \\
\hline 1. & Kedalaman air & $\mathrm{m}$ & Depth meter, insitu \\
2. & Kecerahan & $\mathrm{cm}$ & Cakram Secchi, insitu \\
3. & Suhu air & ${ }^{\circ} \mathrm{C}$ & WQC Horiba U-10, insitu \\
4. & Konduktivitas & $\mathrm{mS} / \mathrm{cm}$ & WQC Horiba U-10, insitu \\
5. & Kekeruhan & $\mathrm{NTU}$ & WQC Horiba U-10, insitu \\
6. & TDS (total dissolved suspended $)$ & $\mathrm{mg} / \mathrm{L}$ & WQC Horiba U-10, insitu \\
7. & Salinitas & ${ }_{0} \%$ & WQC Horiba U-10, insitu \\
8. & pH & unit & WQC Horiba U-10, insitu \\
9. & Oksigen terlarut & $\mathrm{mg} / \mathrm{L}$ & WQC Horiba U-10, insitu \\
\hline
\end{tabular}

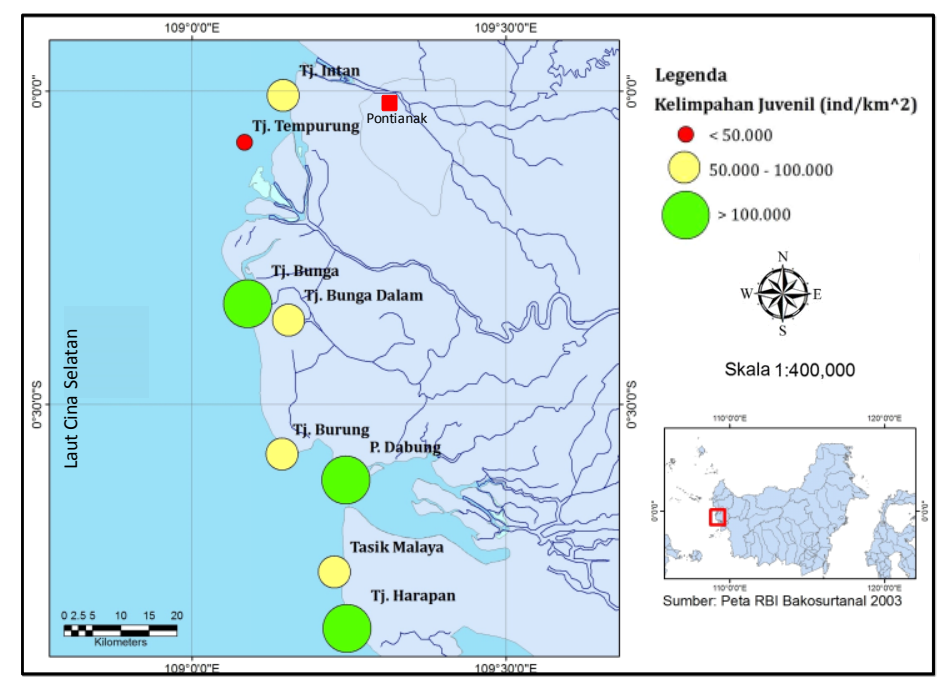

Gambar 2. Kelimpahan juvenil udang Penaidae di perairan Kubu Raya.

Figure 2. Abundance of Penaeidae shrimp juveniles in Kubu Raya waters.

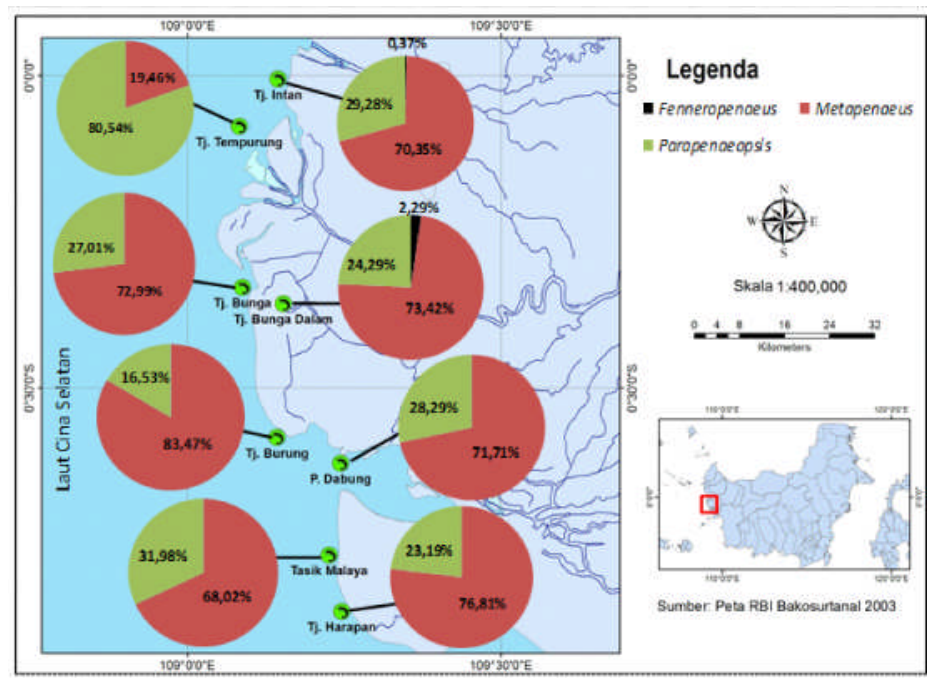

Gambar3. Persentase kelimpahan juvenil udang Penaeidae pada tingkat genus di perairan Kubu Raya.

Figure 3. Percentage of Penaeidae shrimp juveniles of genus level in Kubu Raya waters. 


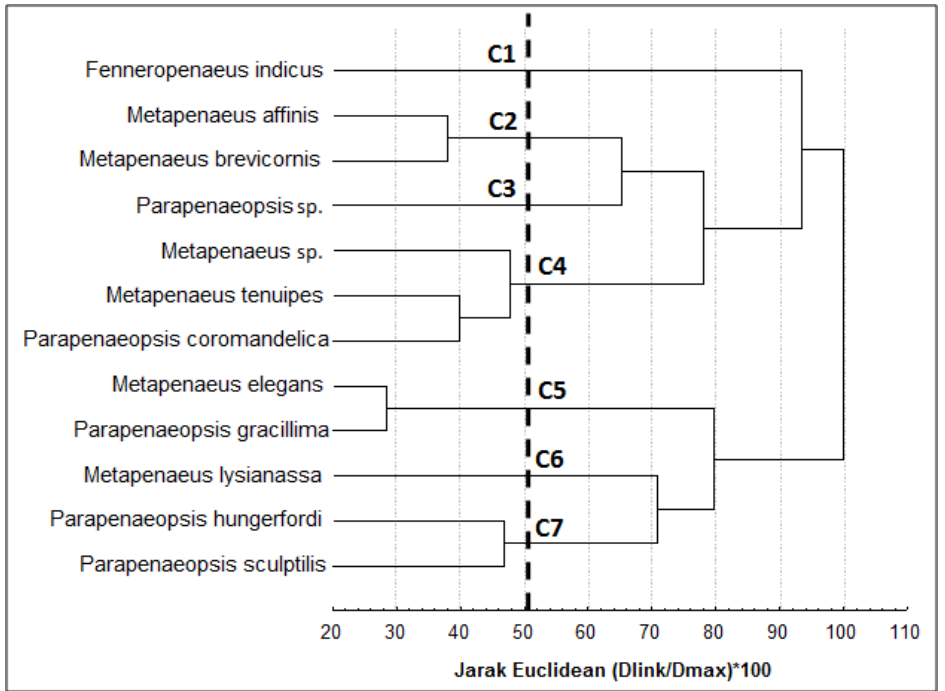

Gambar 4. Dendrogram pengelompokkan udang penaeidae.

Figure 4. Dendrogram on clustering analysis for grouping of penaeid shrimp.

digunakan untuk mengkaji keterkaitan juvenil udang dengan lingkungannya. Diperoleh lima kelompok habitat berdasarkan kualitas air di dasar perairan (Gambar 5).

Analisis nodul berdasarkan indeks constancy dan fidelity yang menghubungkan juvenil udang dan habitatnya tersaji pada Gambar 6. Pola keberadaan (constancy) juvenil udang penaeid di perairan Kubu Raya tergolong kategori antara medium sampai sangat tinggi. Juvenil udang yang memiliki pola keberadaan dengan derajat dispersal tinggi terdapat pada genus Metapenaeus. Kelompok juvenil udang C2-C7 memiliki rata-rata proporsi keberadaan dengan kategori antara sedang sampai sangat tinggi, sedangkan kelompok juvenil udang $\mathrm{C} 1$ memiliki ratarata proporsi keberadaan rendah.
Pola keberadaan yang berbanding lurus terhadap derajat keterkaitan (kategori sedang-sangat tinggi) didapatkan pada dua kelompok juvenil udang, yaitu kelompok juvenil udang $\mathrm{C} 1$ (udang wangkang, $F$. indicus) pada kelompok habitat H1 (Tanjung Intan dan Pulau Dabung) dan H5 (Tanjung Bunga Dalam), serta kelompok juvenil udang C5 (udang dogol putih, M. elegans dan udang rotan, $P$. gracillima) pada kelompok habitat $\mathrm{H} 3$ (Tanjung Tempurung). Derajat keterkaitan (fidelity) jenis udang lainnya tergolong kategori sangat rendah hingga rendah pada kelompok habitat tertentu, walaupun pola keberadaannya tergolong sedang hingga sangat tinggi (Gambar 4).

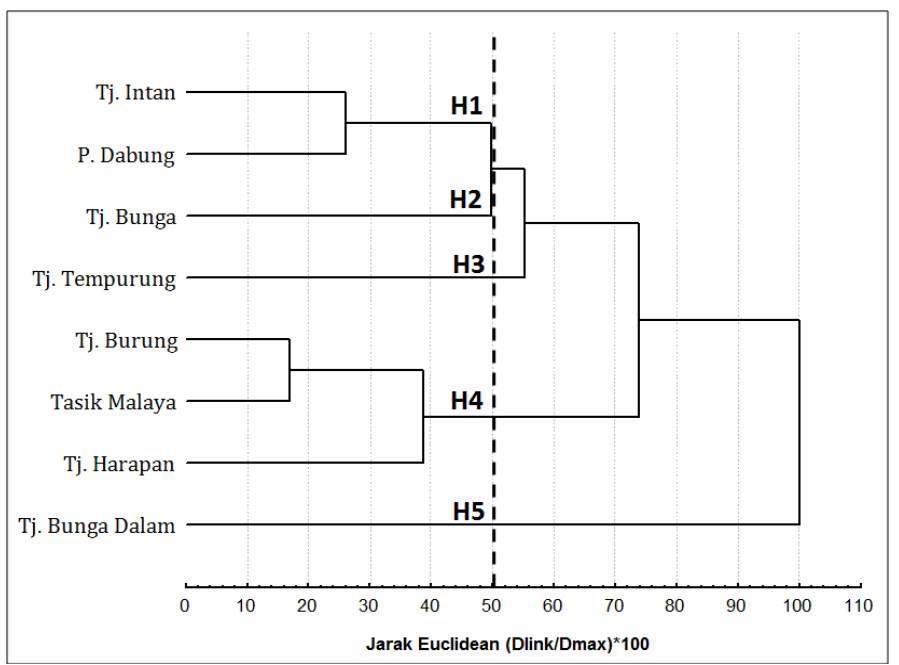

Gambar 5. Dendrogram pengelompokkan habitat udang.

Figure 5. Dendrogram on clustering analysis for shrimp habitat. 


\begin{tabular}{|c|c|c|c|c|c|c|c|c|c|}
\hline & C1 & $C 2$ & C3 & C4 & C5 & C6 & C7 & \multirow{2}{*}{\multicolumn{2}{|c|}{ Keterangan }} \\
\hline H1 & 0.5 & 0.8 & 0.5 & 25 & 25 & 1.0 & 1.0 & & \\
\hline $\mathrm{H} 2$ & 0.0 & 0.5 & 1.0 & 0.7 & 0.5 & 1.0 & 1.0 & $<0,1$ & : sangat rendah \\
\hline H3 & 0.0 & 0.5 & 1.0 & a. & 1.0 & 0.0 & 0.5 & & Fedang \\
\hline $\mathrm{H} 4$ & 0.0 & 0.8 & 1.0 & 0.9 & 0.7 & 1.0 & 0.8 & $\geq 0,5$ & : tinggi \\
\hline H5 & 1.0 & 0.5 & 1.0 & $a$ & 0.0 & 1.0 & 1.0 & $\geq 0,7$ & : sangat tinggi \\
\hline
\end{tabular}

\begin{tabular}{|c|c|c|c|c|c|c|c|c|}
\hline & C1 & $\mathrm{C} 2$ & $\mathrm{C} 3$ & $\mathrm{C4}$ & C5 & C6 & C7 & \multirow{2}{*}{ Keterangan } \\
\hline H1 & Ml & 11 & 0,6 & 0,6 & 0,5 & 11 & 1,2 & \\
\hline H2 & 0,0 & 0,7 & 12 & 1,1 & 20 & i) & 31 & : sangatrenc \\
\hline & 0,0 & 0,7 & 1,1 & 0,6 & III & 0,0 & 0,6 & $\geq 2$ : sedang \\
\hline & 0,0 & 12 & 11 & 15 & 13 & 1. & 10 & $\geq 3$ : tinggi \\
\hline & 4,0 & 0,7 & 31 & 0,6 & 0,0 & 11 & 1,1 & 24 : sangat tinggi \\
\hline
\end{tabular}

Keterangan:

Kelompok Juvenil Udang

C1 Udang wangkang ( $F$. indicus)

C2 Udang dogol (M. affinis), udang kuning (M. brevicornis)

C3 Juvenil udang Parapenaeopsis sp.

C4 Juvenil udang Metapenaeus sp., udang teh (M. tenuipes), udang rotan ( $P$. coromandelica)

Kelompok Habitat

H1 Tj. Intan, P. Dabung

H2 Tj. Bunga

H3 Tj. Tempurung

H4 Tj. Burung, Tasik Malaya, Tj. Harapan

H5 Tj. Bunga Dalam

C5 Udang dogol putih (M. elegans) dan udang rotan $(P$. gracillima)

C6 Udang ambai (M. lysianassa)

C7 Udang merah (P. hungerfordi), udang burik (P. sculptilis)

Gambar 6. Analisis nodul menggunakan indeks constancy (atas) dan indeks fidelity (bawah) pada kelompok udang dan habitatnya.

Figure 6. Nodul analysis using constancy index (above) and fidelity index (below) by shrimp group and habitat.

\section{BAHASAN}

Penyebaran stasiun penelitian di perairan Kubu Raya memiliki karakteristik yang khas. Hal ini karena banyaknya sungai yang bermuara hingga ke daerah estuari. Parameter kualitas air yang berfluktuasi diakibatkan oleh pengaruh massa air sungai dan air laut secara bergantian melalui proses pasang surut serta pengaruh musim. Setiap jenis juvenil udang yang ditemukan cenderung dominan pada stasiun pengamatan tertentu. Hal ini mengindikasikan bahwa seluruh stasiun yang diamati memiliki karakteristik habitat yang berbeda dan khas untuk setiap jenis udang (Macia, 2004).

Pengelompokkan (dendrogram) jenis juvenil udang yang tertangkap menggambarkan kecenderungan sebarannya di setiap habitat yang disukainya. Jenis udang yang berada pada satu kelompok menggambarkan kecenderungan kesamaan sebaran dan pola daur hidup. Hal ini diindikasikan adanya perbedaan persentase kelimpahan dan sebaran antara genus Metapenaeus dan Parapenaeopsis di setiap stasiun (Lampiran 1). Jenis juvenil udang pada setiap kelompok genus menunjukkan adanya kecenderungan akan berkumpul/berkelompok dengan genus yang sama pula.

Penentuan lokasi daerah asuhan (nursery ground) udang tidak lepas dari pengetahuan mengenai pola daur hidup dari jenis udang yang diteliti. Menurut Dall et al. (1990), pola daur hidup udang penaeid dapat dibagi menjadi empat tipe (Lampiran 3). Jenis juvenil udang penaeid yang ditemukan di perairan Kab. Kubu Raya terdiri atas tiga tipe. Tipe 1 terdiri dari dua jenis, yaitu udang dogol putih (M. elegans) dan udang kuning ( $M$. brevicornis). Tipe 2 terdiri dari lima jenis, yaitu udang wangkang ( $F$. indicus), udang dogol (M. affinis), udang 
ambai (M. lysianassa), udang teh (M. tenuipes) dan juvenil udang Metapenaeus sp. Jenis tipe 3 terdiri atas seluruh genus Parapenaeopsis. Adanya perbedaan pola daur hidup menjadikan sebaran juvenil udang Fenneropenaeus, Metapenaeus dan Parapenaeopsis memiliki preferensi habitat yang berbeda.

Analisis indeks constancy dan fidelity menunjukkan beberapa jenis udang memiliki kecenderungan pola sebaran dan preferensi terhadap habitat tertentu. Pola sebaran tersebut tidak selalu berbanding lurus dengan tingkat preferensi habitatnya. Hal ini dikarenakan beberapa jenis udang memiliki penyebaran yang luas dan bersifat kosmopolit. Hal tersebut terutama karena kemampuan untuk mentoleransi salinitas yang tinggi atau euryhaline. Udang Metapenaeus sp. cenderung memiliki kelimpahan yang tinggi dan menyebar di perairan Kubu Raya. Hal ini serupa dengan sebaran dan proporsi keberadaan udang Metapenaeus sp. di Pulau Inhaca, Mozambik, karena sifatnya yang euryhaline dan kosmopolit (Macia, 2004).

Nilai indeks fidelity kurang dari satu mengindikasikan adanya korelasi negatif antara organisme tertentu dengan habitatnya, sedangkan apabila nilai indeks fidelity lebih dari satu maka terdapat korelasi yang positif (Boesch, 1977). Nilai indeks fidelity dengan kategori rendah hingga sangat rendah merupakan indikasi bahwa kelompok juvenil udang tertentu memiliki hubungan negatif untuk derajat preferensi habitatnya, sedangkan kategori sedangsangat tinggi memiliki hubungan positif untuk derajat preferensi habitatnya. Oleh karena itu, juvenil udang wangkang ( $F$. indicus) memiliki korelasi yang positif dengan beberapa lokasi, yaitu perairan Tanjung Bunga Dalam, Tanjung Intan dan Pulau Dabung.

Perairan Tanjung Bunga Dalam merupakan daerah estuari yang dikelilingi banyak mangrove dan mendapat massa air tawar secara langsung. Tipe substrat di perairan Tanjung Bunga Dalam terdiri atas serasah, lumpur dan pasir (Lampiran 1). Hal ini menjadikan daerah Tanjung Bunga sangat cocok sebagai daerah asuhan udang wangkang. Kecenderungan derajat preferensi udang wangkang terhadap habitat lebih tinggi di perairan Tanjung Bunga Dalam daripada Tanjung Intan dan Pulau Dabung. Daerah Tanjung Intan dan Pulau Dabung merupakan daerah asuhan lainnya bagi udang wangkang dengan kategori keterkaitan terhadap habitat bersifat medium. Lokasi tersebut lebih dipengaruhi oleh massa air laut daripada air sungai, sehingga derajat preferensi udang wangkang cenderung bersifat medium. Sifat kedua lokasi yang terbuka memungkinkan pengaruh laut cukup tinggi, terutama ketika terjadi pasang.

Densitas beberapa jenis udang penaeid diketahui memiliki korelasi positif dengan keberadaan mangrove (Baran, 1999). Sebaran udang wangkang (F. indicus) memiliki tingkat penyebaran dan keterkaitan yang berkorelasi positif dengan keberadaan mangrove (Teikwa \& Mgaya, 2003). Udang F. indicus pada fase postlarva, juvenil, dan sub-dewasa lebih memanfaatkan daerah mangrove bagian dalam (Ronnback et al., 2002). Lebih lanjut, udang $F$. indicus memiliki preferensi yang tinggi terhadap daerah pinggiran mangrove, adanya masukan air sungai dengan substrat dominan berupa pasir bercampur lumpur (Macia, 2004). Karakter utama habitat daerah asuhan udang wangkang di perairan Kubu Raya adalah daerah estuari dengan kerapatan mangrove cukup tinggi, mendapat massa air tawar secara langsung dengan tipe substrat dominan pasir bercampur lumpur dan serasah.

Jenis udang lainnya yang memiliki korelasi positif dengan habitatnya adalah udang dogol putih (M. elegans) dan udang rotan ( . gracillima) di daerah perairan Tanjung Tempurung. Daerah ini merupakan perairan estuaria yang mendapat banyak masukan massa air tawar dan air laut yang cukup tinggi dengan kedalaman cenderung landai. Udang dogol putih (M. elegans) memiliki tingkat preferensi habitat kategori medium di lokasi tersebut. Udang ini memiliki daur hidup tipe 1 , sehingga cenderung memilih daerah asuhan ke arah estuaria dan muara sungai. Penelitian di Segara Anakan, Cilacap oleh Saputra et al. (2005) diperoleh hasil bahwa udang M. elegans hampir seluruh hidupnya berada di perairan estuari. Jenis udang rotan $(P$. gracillima) memiliki sifat yang berkebalikan dengan udang $M$. elegans. Juvenil udang rotan memiliki pola daur hidup tipe 3 dan cenderung memilih daerah asuhan dengan salinitas tinggi atau lebih ke tengah (arah laut). Sifat ini kurang lebih sama dengan jenis udang penaeid lainnya yang memiliki pola daur hidup tipe 3 (Khorshidian, 2002). Karakter utama habitat daerah asuhan udang dogol putih dan rotan di perairan Kubu Raya adalah daerah estuaria yang memiliki banyak masukan massa air tawar dan air laut atau sangat dipengaruhi oleh proses pasang-surut, kedalaman cenderung landai dan tipe substrat terdiri dari lumpur dan pasir serta banyak serasah.

\section{KESIMPULAN}

Juvenil udang dari genus Fenneropenaeus, Metapenaeus dan Parapenaeopsis memiliki pola sebaran yang berbeda pada habitat tertentu karena memiliki perbedaan tipe siklus hidup. Juvenil udang wangkang (Fenneropenaeus indicus) memiliki derajat keterkaitan terhadap habitat dengan kategori sangat tinggi di perairan Tanjung Bunga Dalam, sedangkan derajat keterkaitan dengan kategori medium terdapat di perairan Tanjung Intan dan Pulau Dabung. Udang dogol putih (Metapenaeus elegans) dan udang rotan (Parapenaeopsis gracillima) memiliki derajat keterkaitan terhadap habitat dengan kategori medium terdapat di perairan Tanjung Tempurung. 


\section{PERSANTUNAN}

Tulisan ini merupakan kontribusi dari kegiatan penelitian "Pengkajian Kesesuaian Pantai Kalimantan Barat sebagai Kawasan Refugia Udang” T.A. 2012-2013, di Balai Penelitian Pemulihan dan Konservasi Sumber Daya Ikan-Jatiluhur, Purwakarta.

\section{DAFTAR PUSTAKA}

Baran, E., 1999. A review of quantified relationships between mangroves and coastal resources. Phuket Marine Biological Center Research Bulletin. 62: 5764.

Boesch, D. F. 1977. Application of numerical classification in ecological investigations of water pollution. Environmental Research Laboratory Office of Research and Development. Oregon: U.S. Environmental Protection Agency: 126 p.

Chan, T. Y. 1998. Shrimp and prawn. in Carpenter, K. E. \& V. H. Niem. (Ed.). 1998. FAO Species identification guide for fishery purposes-the living marine resources of the Western Central Pacific Vol. 2 cephalopods, crustaceans, holothurians and sharks: FAO. Rome: $687-1396$.

Dall, W., B. J. Hill, P. C. Rothlisberg \& D. J. Staples. 1990. The biology of the penaeidae. in Blaxter, J. H. S. \& A. J. Southward. Eds. Advances in marine biology, Vol. 27. Academic Press Inc. London: 489 p.

Dinas Perikanan \& Kelautan Kabupaten Kubu Raya. 2011. Penyusunan rencana kawasan konservasi laut daerah (KKLD) Kabupaten Kubu Raya Provinsi Kalimantan Barat. Laporan Penelitian. Pontianak. Kalimantan Barat: $351 \mathrm{p}$.

Fischer, W. \& G. Bianchi. (Ed.). 1984. FAO Species identification sheets for fishery purposes, Western Indian Ocean (fishing area 51). Prepared and printed with the support of the Danish International Development Agency (DANIDA), Rome, Food and Agriculture Organization of the United Nations, Vols. 1-6: pag. var.

Holthuis, L. B. 1980. FAO Species catalogue, shrimps and prawns of the world-an annotated catalogue of species of interest to fisheries. FAO. Fish. Synop. 125(1): 271 p.

Kembaren, D. D. 2012. Aspek biologi udang dogol (Metapenaeus ensis) di perairan Pemangkat, Kalimantan Barat. Prosiding. Seminar Nasional Perikanan Tangkap: 357-365.
Khorshidian, K. 2002. Biological characteristics of commercially exploited penaeidae shrimp (Penaeus semisulcatus) in the North-Western part of the Persian Gulf. Final Project. UNU-Fisheries Training Programme. The United Nations University: 41 p.

Krebs, C. J. 1989. Ecological methodology. Harper Collins Publisher Inc. New York: 666 p.

Macia, A. 2004. Juvenile penaeid shrimp density, spatial distribution and size composition in four adjacent habitats within a mangrove-fringed bay on Inhaca Island, Mozambique. Western Indian Ocean J. Mar. Sci. 3 (2): 163-178.

Nielsen, L. A. \& D. L. Johnson. 1985. Fisheries techniques. American Fisheries Society, Bethesda, Maryland: 468 p.

Palomares, M. L. D. \& D. Pauly. Eds. 2012. SeaLifeBase. World Wide Web electronic publication. www.sealifebase.org, version $(06 / 2012)$.

Ronnback, P., A. Macia, G. Almqvist, L. Schultz \& M. Troell. 2002. Do penaeid shrimps have a preference for mangrove habitats? distribution pattern analysis on Inhaca Island, Mozambique. Estuarine, Coastal and Shelf Science 55: 427-436.

Saputra, S. W., S. Sukimin, M. Boer, R. Affandi \& D. R. Monintja. 2005. Aspek reproduksi dan daerah pemijahan udang jari (Metapenaeus elegans De Man, 1907) di Laguna Segara Anakan, Cilacap, Jawa Tengah. Ilmu Kelautan. 10 ( 1): 41-49.

Saptoyo. 2006. Study on capture of small white shrimp (Metapenaeus lysianassa, de man 1888) as a management application in Sungai Kakap Estuary Kabupaten Pontianak West Kalimantan. Thesis. Marine and Coastal Resources Management. Bogor: Bogor Agricultural University: $60 \mathrm{p}$.

Spare, P. \& S. C. Venema. 1992. Introduksi pengkajian stok ikan tropis. Buku 1. Manual. Jakarta: Pusat Penelitian dan Pengembangan: 438 p.

Teikwa, E. D. \& Y. D. Mgaya., 2003. Abundance and reproductive biology of the penaeid prawns of Bagamoyo Coastal waters, Tanzania. Western Indian Ocean J. Mar. Sci. 2 (2): 117-126.

United Nation Environment Program (UNEP). 2007. Procedure for establishing a regional system of fisheries refugia in the South China Sea and Gulf of Thailand in the context of the UNEP/GEF project entitled: "reversing environmental degradation trends 
in the South China Sea and Gulf of Thailand". South China Sea Knowledge Document (4), UNEP/GEF/SCS/ Inf.4: $19 \mathrm{p}$.

United Nation Environment Program (UNEP). 2009. Reversing environmental degradation trends in the South China Sea and Gulf of Thailand. Terminal Evaluation, International Waters Project. GEF Project ID: 885, UNEP Project ID: 248: $60 \mathrm{p}$.
Wedjatmiko, Suprapto \& P. Lestari. 2011. Status daerah asuhan udang penaeid di perairan Pemangkat, Kalimantan Barat. in Kartamihardja, E. S. et al. Eds. Prosiding. Forum Nasional Pemacuan Sumber Daya Ikan III: $10 \mathrm{p}$. 
Hedianto, D.A., et al / BAWAL Vol. 6 (2) Agustus 2014 : 77-88

Lampiran 1. Sebaran dan kelimpahan rata-rata juvenil udang penaeid di perairan Kubu Raya

Appendix 1. Average abundance and distribution of juvenile penaeid shrimps in Kubu Raya waters

\begin{tabular}{|c|c|c|c|c|c|c|c|c|c|}
\hline \multirow{2}{*}{$\begin{array}{l}\text { Jenis Udang/ } \\
\text { Local Name }\end{array}$} & \multirow{2}{*}{$\begin{array}{c}\text { Spesies/ } \\
\text { Shrimp Species }\end{array}$} & \multicolumn{8}{|c|}{$\begin{array}{c}\left.\text { Kelimpahan (ind } / \mathrm{km}^{2}\right) / \\
\text { Abundance }\left(\text { ind } / \mathrm{km}^{2}\right)\end{array}$} \\
\hline & & $\mathbf{A}$ & B & $\mathbf{C}$ & D & $\mathbf{E}$ & $\mathbf{F}$ & $\mathbf{G}$ & $\mathbf{H}$ \\
\hline \multicolumn{2}{|c|}{ Genus Fenneropenaeus } & 275 & - & - & 1.451 & - & - & - & - \\
\hline Udang Wangkang & $F$. indicus & 275 & - & - & 1.451 & - & - & - & - \\
\hline \multicolumn{2}{|c|}{ Genus Metapenaeus } & 51.929 & 8.085 & 79.930 & 46.491 & 51.959 & 84.966 & 58.408 & 111.435 \\
\hline Udang Dogol & M. affinis & 5.953 & 2.878 & 3.563 & 850 & 4.516 & 849 & 4.817 & 6,073 \\
\hline Udang Kuning & M. brevicornis & 2.060 & 88 & 94 & 188 & 98 & - & 580 & 1,777 \\
\hline Udang Dogol Putih & M. elegans & 95 & 388 & - & - & - & - & 3.302 & - \\
\hline Udang Ambai & M. lysianassa & 27.140 & 4.248 & 20.827 & 27.952 & 39.589 & 81.699 & 33.830 & 37,425 \\
\hline Udang T & M. tenuipes & - & - & - & - & - & - & 377 & 727 \\
\hline Juvenil Udang_1 & Metapenaeus sp. & 16.680 & 485 & 55.445 & 17.501 & 7.757 & 2.418 & 15.502 & 65,433 \\
\hline \multicolumn{2}{|c|}{ Genus Parapenaeopsis } & 21.612 & 33.462 & 29.577 & 15.381 & 10.292 & 33.522 & 27.455 & 33.640 \\
\hline Udang Rotan & P. coromandelica & 92 & 1.386 & 4.964 & - & 4.373 & 5.700 & 1.912 & 13,697 \\
\hline Udang Rotan & P. gracillima & 75 & 440 & 586 & - & 295 & 609 & 1.677 & 728 \\
\hline Udang Merah & P. hungerfordi & 7.204 & 7.263 & 16.304 & 8.585 & 819 & 25.340 & 19.550 & 5,048 \\
\hline Udang Burik & P. sculptilis & 286 & 88 & 1.321 & 400 & 295 & 661 & 636 & 211 \\
\hline Juvenil Udang_2 & Parapenaeopsis sp. & 13.956 & 24.286 & 6.403 & 6.396 & 4.510 & 1.212 & 3.679 & 13,955 \\
\hline \multicolumn{2}{|c|}{ Total } & $\mathbf{7 3 . 8 1 5}$ & 41.548 & 109.507 & 63.323 & 62.251 & 118.489 & 85.863 & 145.076 \\
\hline
\end{tabular}

Ket: $\quad A=T j$. Intan; $B=T j$. Tempurung; $C=T j$. Bunga; $D=T j$. Bunga Dalam; $E=T j$. Burung;

$\mathrm{F}=\mathrm{P}$. Dabung; $\mathrm{G}=$ Tasik Malaya; $\mathrm{H}=\mathrm{Tj}$. Harapan 
Lampiran 2. Kualitas air menurut stasiun penelitian di perairan Kubu Raya Appendix 2. $\quad$ Water quality by sampling site in Kubu Raya waters

\begin{tabular}{|c|c|c|c|c|c|c|c|c|c|c|}
\hline \multirow{2}{*}{$\begin{array}{l}\text { No./ } \\
\text { No }\end{array}$} & \multirow{2}{*}{\multicolumn{2}{|c|}{$\begin{array}{c}\text { Parameter/ } \\
\text { Parameter }\end{array}$}} & \multicolumn{8}{|c|}{$\begin{array}{l}\text { Stasiun Penelitian/ } \\
\text { Research Station }\end{array}$} \\
\hline & & & $\mathbf{A}$ & B & C & D & $\mathbf{E}$ & $\mathbf{F}$ & $\mathbf{G}$ & $\mathbf{H}$ \\
\hline \multirow[t]{3}{*}{1.} & Kedalaman & Min & 1,2 & 1,7 & 1,3 & 2,1 & 2,0 & 2,0 & 2,0 & 2,0 \\
\hline & $(\mathrm{m})$ & Max & 3,4 & 3,8 & 3,7 & 4,6 & 3,4 & 4,4 & 3,0 & 2,6 \\
\hline & & Rerata & 2,4 & 2,8 & 2,1 & 3,4 & 2,6 & 3,0 & 2,6 & 2,2 \\
\hline \multirow[t]{3}{*}{2.} & Kecerahan & Min & 35,0 & 30,0 & 40,0 & 20,0 & 60,0 & 50,0 & 40,0 & 40,0 \\
\hline & $(\mathrm{cm})$ & $\operatorname{Max}$ & 200,0 & 290,0 & 220,0 & 110,0 & 215,0 & 100,0 & 150,0 & 90,0 \\
\hline & & Rerata & 91,3 & 120,8 & 106,7 & 60,0 & 99,0 & 76,7 & 80,0 & 59,0 \\
\hline \multirow[t]{3}{*}{3.} & Suhu Air & Min & 29,7 & 28,2 & 29,6 & 28,8 & 28,1 & 29,5 & 28,9 & 28,3 \\
\hline & $\left({ }^{\circ} \mathrm{C}\right)$ & $\operatorname{Max}$ & 31,3 & 30,4 & 30,6 & 30,5 & 31,0 & 32,4 & 30,8 & 30,4 \\
\hline & & Rerata & 30,3 & 29,3 & 30,1 & 29,6 & 29,7 & 30,7 & 29,7 & 29,5 \\
\hline \multirow[t]{3}{*}{4.} & Konduktivitas & Min & 8,2 & 11,6 & 10,5 & 0,1 & 21,5 & 18,3 & 21,1 & 21,1 \\
\hline & $(\mathrm{mS} / \mathrm{cm})$ & $\operatorname{Max}$ & 48,2 & 50,3 & 53,2 & 44,3 & 52,0 & 44,7 & 50,4 & 50,9 \\
\hline & & Rerata & 36,7 & 36,2 & 33,9 & 15,6 & 40,9 & 35,9 & 39,1 & 39,8 \\
\hline \multirow[t]{3}{*}{5.} & Kekeruhan & Min & 6,5 & 0,0 & 0,0 & 16,5 & 3,5 & 12,8 & 18,5 & 18,5 \\
\hline & (NTU) & Max & 98,8 & 25,9 & 85,4 & 124,0 & 84,2 & 45,3 & 76,5 & 74,8 \\
\hline & & Rerata & 35,2 & 12,6 & 24,9 & 48,8 & 43,5 & 27,5 & 34,7 & 48,6 \\
\hline \multirow[t]{3}{*}{6.} & TDS & Min & 5,3 & 7,2 & 6,5 & 0,1 & 13,3 & 11,3 & 13,1 & 0,3 \\
\hline & $(\mathrm{g} / \mathrm{L})$ & Max & 29,0 & 30,1 & 72,9 & 29,1 & 30,9 & 28,9 & 29,5 & 28,7 \\
\hline & & Rerata & 23,1 & 22,7 & 31,2 & 14,8 & 25,6 & 22,4 & 24,4 & 18,9 \\
\hline \multirow[t]{3}{*}{7.} & Salinitas & Min & 4,9 & 11,9 & 5,9 & 0,0 & 12,9 & 10,8 & 12,3 & 12,6 \\
\hline & $(\% o)$ & Max & 30,1 & 31,3 & 31,1 & 28,2 & 30,9 & 28,6 & 30,2 & 30,5 \\
\hline & & Rerata & 23,8 & 23,9 & 21,9 & 10,2 & 26,1 & 22,4 & 24,8 & 25,3 \\
\hline \multirow[t]{3}{*}{8.} & $\mathrm{pH}$ & Min & 7,3 & 7,2 & 7,1 & 6,1 & 8,1 & 7,8 & 8,0 & 8,1 \\
\hline & (unit) & $\operatorname{Max}$ & 8,4 & 8,4 & 8,4 & 8,3 & 8,5 & 8,4 & 8,5 & 8,5 \\
\hline & & Rerata & 8,0 & 7,9 & 8,0 & 7,1 & 8,2 & 8,1 & 8,2 & 8,3 \\
\hline \multirow[t]{3}{*}{9.} & Oksigen Terlarut & Min & 4,1 & 3,6 & 4,9 & 3,4 & 4,5 & 4,6 & 4,5 & 5,1 \\
\hline & $(\mathrm{mg} / \mathrm{L})$ & $\operatorname{Max}$ & 8,1 & 8,1 & 7,1 & 6,1 & 8,3 & 7,5 & 9,0 & 9,0 \\
\hline & & Rerata & 5,2 & 4,9 & 6,0 & 4,8 & 6,2 & 5,4 & 6,1 & 6,6 \\
\hline 10. & Sedimen & & $\begin{array}{l}\text { Lumpur, } \\
\text { Pasir }\end{array}$ & $\begin{array}{l}\text { Serasah, } \\
\text { Pasir, } \\
\text { Lumpur }\end{array}$ & $\begin{array}{l}\text { Pasir, } \\
\text { Lumpur }\end{array}$ & $\begin{array}{l}\text { Lumpur, } \\
\text { Pasir, } \\
\text { Serasah }\end{array}$ & Pasir & $\begin{array}{l}\text { Lumpur, } \\
\text { Pasir }\end{array}$ & Pasir & Pasir \\
\hline
\end{tabular}

Ket: $\quad A=T j$. Intan; $B=T j$. Tempurung; $C=T j$. Bunga; $D=T j$. Bunga Dalam; $E=T j$. Burung;

$\mathrm{F}=\mathrm{P}$. Dabung; $\mathrm{G}=$ Tasik Malaya; $\mathrm{H}=\mathrm{T} \mathrm{j}$. Harapan 
Lampiran 3. Klasifikasi pola daur hidup udang penaeid (Dall et al., 1990)

Appendix 3. Classification of life history patterns of Penaeid shrimp (Dall et al., 1990)

\begin{tabular}{|c|c|}
\hline $\begin{array}{l}\text { Pola Daur Hidup/ } \\
\text { Life History Patterns }\end{array}$ & $\begin{array}{c}\text { Deskripsi// } \\
\text { Descriptions }\end{array}$ \\
\hline Tipe 1 & $\begin{array}{l}\text { Hampir seluruh fase daur hidup udang berada di estuari dan muara sungai. } \\
\text { Beberapa dari jenis udang tipe ini mungkin bermigrasi ke daerah perairan pantai } \\
\text { yang terlindung untuk bertelur, dengan sifat telur tidak sepenuhnya bersifat } \\
\text { demersal. Postlarva cenderung bermigrasi ke arah sungai dengan salinitas rendah } \\
\text { (euryhaline). Setelah tumbuh menjadi juvenil, bergerak kembali ke arah muara } \\
\text { sungai dengan salinitas yang lebih tinggi. }\end{array}$ \\
\hline Tipe 2 & $\begin{array}{l}\text { Udang memiliki fase hidup antara estuaria dan laut. Udang yang siap memijah akan } \\
\text { bermigrasi dari estuaria, beberapa spesies cenderung mendekati perairan pantai } \\
\text { yang tertutup, sedangkan beberapa spesies lainnya akan bermigrasi ke perairan laut } \\
\text { dalam untuk memijah. Fase postlarva bermigrasi kembali ke estuaria sebagai lokasi } \\
\text { nursery ground. Udang yang masuk tipe ini bersifat euryhaline, dimana beberapa } \\
\text { spesies memiliki telur yang bersifat pelagis. }\end{array}$ \\
\hline Tipe 3 & $\begin{array}{l}\text { Udang cenderung menyukai salinitas tinggi dan bersifat stenohaline, sehingga } \\
\text { tahapan dari siklus hidupnya sangat sedikit juvenil yang menjadikan nursery } \\
\text { ground di daerah estuaria. Pada tahap postlarva dan juvenil berada di pantai, } \\
\text { kemudian udang dewasa memijah di dasar perairan lepas pantai. Fase postlarva } \\
\text { bermigrasi ke perairan pantai yang dangkal, seringkali di daerah lamun dan } \\
\text { komunitas alga dengan kadar salinitas yang tinggi, migrasi ke lepas pantai mirip } \\
\text { dengan udang penaeid tipe } 2 \text {. Beberapa spesies memiliki telur yang bersifat pelagis. }\end{array}$ \\
\hline Tipe 4 & $\begin{array}{l}\text { Seluruh daur hidup berada di lepas pantai ( offshore). Jenis ini kemungkinan tidak } \\
\text { memiliki fase bentik (indikasi adanya daur hidup yang terpisah). Beberapa spesies } \\
\text { lainnya berada di laut dalam pada fase juvenil bentik dan dewasa, jenis telur pada } \\
\text { dua sub-grup bersifat pelagis. }\end{array}$ \\
\hline
\end{tabular}

